\title{
EMBRACING AFRICAN LANGUAGES AS INDISPENSABLE RESOURCES THROUGH THE PROMOTION OF MULTILINGUALISM
}

\author{
Nobuhle Ndimande-Hlongwa \& Hloniphani Ndebele \\ University of KwaZulu-Natal, South Africa
}

This paper seeks to explore the potential significance of additive multilingualism in South Africa's multilingual society. Additive multilingualism treasures the principle of equality among all 11 official languages. Therefore, our point of departure is the South African Constitution and various policy provisions that advocate for a multilingual mode of operation. The paper is premised upon the potential value of multilingualism that encompasses indigenous African languages and the view of language as a resource. This concurs with the language policy of the University of KwaZulu-Natal (UKZN), which seeks to promote a multilingual society. Perceptions and experiences of a group of part-time LLB students regarding the learning of isiZulu as an additional language at UKZN were solicited in this study. The 'language as a resource' framework was employed as the theoretical approach of the study. The study established an acknowledgement of the resourcefulness of isiZulu as instrumental in fostering social cohesion, breaking communication barriers, and dispelling misconceptions about the value of these languages.

Keywords: additive multilingualism; additional languages; indigenous African languages; language policy; higher education.

\section{INTRODUCTION}

Indigenous African languages are unquestionably an integral constituent of South Africa's multilingual diversity. It is important for this diversity to be manifested among speakers of different languages. The colonial and apartheid systems enforced monolingualism and a type of bilingualism which favoured English and Afrikaans, while African languages were denied space to operate in official domains. However, in the post-democratic era, some higher education institutions in South Africa have positioned themselves well as stakeholders in the promotion of multilingualism by adopting an additive multilingual approach. In additive multilingualism, other languages are added to a speaker's linguistic repertoire while the first language is developed. This usually happens when speakers of a dominant language acquire other languages (Cenoz, 2013). An additive multilingual approach is thus a departure and break from the oppression of colonial and apartheid monolingualism and bilingualism (Pluddemann, 1997). As such, the University of KwaZulu-Natal (UKZN), in line with its language policy, has demonstrated commitment to the cause through the teaching of isiZulu as an additional language to non-Nguni mother tongue speakers. It is upon such a basis that this paper seeks to explore the potential value of multilingualism that encompasses indigenous African languages through the views and experiences of isiZulu additional language adult students. 


\section{BACKGROUND INFORMATION}

South Africa's 'rainbow nation' trait is evident in its linguistic and cultural diversity which formed the foundation of South Africa's democracy, with nine indigenous African languages, English, and Afrikaans granted official recognition. It is important to highlight at this stage that, dating back to the colonial and apartheid era, indigenous African languages played and continue to play second fiddle to English and Afrikaans. This is despite the presence of empowering legislative and policy provisions that advocate for equality and parity of esteem in the use of all 11 official languages. In this regard, scholars have argued that, instead of linguistic pluralism, monolingualism is becoming an acceptable norm, while indigenous African languages continue to be marginalised (Alexander, 2013; Madiba, 2010).

The marginalisation of indigenous African languages has influenced negative attitudes towards them. Various research studies have revealed that even mother tongue African language speaking parents and students often opt for English as language of teaching and learning as opposed to their mother tongue (Barkhuizen, 2001; De Klerk, 1996, 2000; Dyres, 1998; Heugh, 2000; Webb, 1996). Given such a context, non-mother tongue speakers of indigenous African languages would naturally see no value in learning these languages. These attitudes have no doubt contributed negatively to the status of these languages as functional languages. Moreover, Mazrui and Mazrui (1998) argue that the hegemonic nature of English, imposed through colonialism in Africa, has had a result of unquestionable prestige associated with English, which has the disastrous effect of distorting educational possibilities and weakening the value which African languages possess. They add that this weakening has instigated psychological harm, so much so that many speakers of these languages have accepted their fate as basically inferior to English.

There are, however, many policy and legislative provisions that support the promotion of multilingualism in South African as opposed to the further enhancement of English and Afrikaans hegemony. The South African democratic Constitution provides a firm foundation for multilingualism by according official recognition to 11 languages, of which nine are indigenous African languages. Section 6(2) of the Constitution states that, in 'recognising the historically diminished use and status of indigenous languages of our people, the state must take practical and positive measures to elevate the status and advance the use of these languages' (South Africa, 1996). The National Language Policy Framework is also a major document that obligates different government departments to a multilingual mode of operation (Department of Arts and Culture, 2002). More recently, the government introduced the Use of Official Languages Act (South Africa, 2012), which provides mechanisms for the implementation of multilingualism in government institutions, government departments and the private sector.

Within the higher education context, many other policy documents have been formulated in the democratic era. These include, among others, the Higher Education Act of 1997; the Language Policy for Higher Education, 2002; the Ministerial Report on the Development of Indigenous African Languages as Mediums of Instruction in Higher Education, 2003; the Report of the Ministerial Committee on Transformation and Social Cohesion and the Elimination of Discrimination in Public Higher Education Institutions, 2008; the Report for the Charter for the Humanities and Social Sciences, 2011; and the White Paper for Post-

Per Linguam 2017 33(1):67-82

http://dx.doi.org/10.5785/33-1-692 
School Education and Training, 2013. All the above policy documents share a common objective of a multilingual South Africa that embraces linguistic diversity.

However, it is important to highlight that, despite the presence of the abovementioned legislative provisions, there is still a large visible gap between policy and implementation. This has seen the maintaining of the status quo which enforces the dominance of English while indigenous African languages continue to suffer marginalisation in higher education. In support of the above, it is argued that the lack of commitment in implementing the above mentioned policies has resulted in 'paper policy' which encourages language death. Therefore, there is a need for collaboration involving the government, the private sector, and the higher education institutions in the implementation processes (Kaschula, 2004; Swanepoel, 2011). Several scholars, such as Alexander (2002), Bamgbose (1991), Kaschula (2004), and Webb (2002) also agree on the assertion that many countries and institutions in Africa possess comprehensive language policies but nevertheless need to come up with sound implementation plans.

In the following section, we seek to explore the concept of multilingualism and the potential of African languages in a multilingual country such as South Africa. We also discuss various initiatives by higher education institutions whose objective is promoting multilingualism through additional African language learning.

\section{Multilingualism and indigenous African languages}

Different countries in the world have approached the issue of multilingualism in different ways, with two leading scenarios emerging in this regard. The first scenario is where a country has a dominant language spoken by the majority of the population but desires multilingual citizens who possess the capacity to adequately communicate in different other languages. Such a situation is prevalent in European countries such as Finland, Denmark and the Netherlands. The second scenario, characterised by a country with many languages and a strong desire that all citizens acquire one or more additional languages, is typical of African countries (Van Ginkel, 2014). In the second scenario, the colonial language has had a strong influence on citizens' beliefs and views about languages. According to Djite (2008), the colonial language is frequently associated with socio-economic development and success while indigenous African languages are accorded no value.

As Webb (1996) argues, English has an exceptionally high status in the South African context. It is not only regarded as the major economic, educational, and social language, but has also become a symbol of the struggle against apartheid and of liberation. The promotion of multilingualism that encompasses indigenous African languages, under such circumstances, seems to be an insurmountable task. May (2004:41) argues that elevating English as a 'majority language' exacerbates the continued disregard for indigenous African languages, whereas encouraging indigenous language speakers to assert their right to hear, speak, read, and learn in their own language may be interpreted as restricting such speakers within the boundaries of a language that lacks wider use and limits social mobility. Under such circumstances, an ideal approach could entail accepting and advancing the functional capacity of English, while simultaneously accepting and advancing the status, value, 
accessibility and functional capacity of indigenous African languages, thus significantly contributing to an ideal multilingual society.

Webb (1996:146) posits that a language is a fountain of community development which provides access to economic opportunities, as well as educational, social, political, and cultural participation. It is therefore necessary to reflect the degree to which indigenous African languages are viewed as necessary and important in everyday livelihood for cognitive, socio-cultural and economic benefit for both mother tongue and non-mother tongue speakers. According to Alexander, the value of a language is created; a language does not acquire value automatically (Alexander, 2013:102-105). He further argues that (Alexander, 2013:108):

Unless African languages are given market value, that is, unless their instrumentality for processes of production, exchange and distribution is enhanced, no amount of policy change...can guarantee their use in high functions and, thus, eventual escape from dominance and hegemony of English.... [The] current language-medium practices cause cognitive impoverishment and, consequently, necessitate investment in compensatory on-the-job training.... This wastefulness would have been avoidable if there had been a national development plan in which reform of education and economic development planning were integrated.

Scholars have emphasised the importance of embracing multilingualism through the promotion of indigenous African languages. Mavesera (2011) argues that the modern workplace is characterised by a search for knowledge and information, which demands that workers should be able to communicate, handle information, and adapt to new developments. Taking into consideration the fact that African language speakers from various language groups in Africa contribute to the highest percentage of workforce in industries in South Africa, communication in African languages would enhance productivity. Certain workplace hazards could be minimised or eliminated if African languages were used for information dissemination in the workplace (Mavesera, 2011). Furthermore, linguistic and cultural diversity are indispensable facets in guaranteeing the endurance of human beings in their societies (Alexander, 2007). Language and culture are closely related because language is a carrier of culture. Language is a tool that people use to pronounce their belonging to a particular community and culture. The loss of one language means a loss of part of the national cultural treasure (Chumbow, 2009). In addition, multilingualism should be considered an asset, as opposed to an impediment, to the achievement of national unity, development, political association, nation building, and social integration. The premise is that all languages in a linguistically diverse community have a right to existence and should be granted a fair opportunity to develop terminology in higher-domain fields, such as the legal and technological fields (Mazrui and Mazrui, 1998).

In an attempt to promote multilingualism through the use of indigenous African languages in South Africa, different higher education institutions have been involved in various initiatives aimed at facilitating additional language acquisition. One of the notable projects is the South Africa-Norway Tertiary Development Programme (SANTED) that took place from 2007 to 2009. The collaborative project which involved higher education institutions in the province of KwaZulu-Natal was entitled 'Multilingualism to Promote Access, Retention and 
Successful Professional Training', and its broad aim was promoting multilingualism in higher education. The promotion of multilingualism involved the provision of short courses for students undertaking professional degrees, such as health sciences and psychology, to learn additional languages that would help them communicate with clients for effective service delivery (Ndimande-Hlongwa \& Wildsmith, 2010). The medium- to long-term objectives of the SANTED project were to develop and promote elevated levels of isiZulu language proficiency, to produce graduates with skilled professional interaction in isiZulu and English, and to contribute towards developing a specialised discourse in isiZulu for selected disciplines (Ndimande-Hlongwa \& Wildsmith, 2010).

Various other initiatives have been witnessed in different colleges of the UKZN. The discipline of African languages has produced a CD-ROM and manual for the teaching and learning of isiZulu as an additional language for learners and staff. The discipline also collaborates with other disciplines in other colleges in the development of discipline specific terminologies. The College of Health Sciences has formulated strategies of addressing the language needs of both staff and students in an 'isiZulu for professional purposes' course. Moreover, the objective-structured clinical examination in the clinical skills laboratory initiative, which involves the testing of clinical skills, has been incorporated into the new curriculum at the medical school (Kamwendo, Hlongwa \& Mkhize, 2014). The UKZN Extended Learning Unit has also rolled out a basic isiZulu course for all staff members at the university, as well as innovative language learning programmes in isiZulu for Nursing and Psychology (Hlongwa \& Mazibuko, 2016).

Another notable initiative within the overall higher education domain is the establishment of the National Research Foundation SAR Chi Chair: Intellectualisation of African Languages, Multilingualism and Education, and the CEPD Catalytic projects. The major objective of this initiative is the facilitation of theoretical debates within various fields that include applied language studies, theoretical linguistics, African literary studies, and second language teaching and learning. With regard to second and additional African language learning, the intention is to explore the development of vocation-specific curricula for additional African language speakers and learners. Courses are being designed in isiXhosa, and these can be replicated in other languages to assist in professional communication in fields such as law, pharmacy, education, and psychology (Kaschula \& Maseko, 2014).

Some universities have demonstrated commitment to enhancing the work of the Chair and the Catalytic Project as aforementioned. For example, medical students at the University of Cape Town cannot graduate without undergoing Afrikaans and isiXhosa on-site clinical examinations, which empower students with required language skills for patient examination (Reynecke \& Claasen, 2015). The Centre for African Language Diversity and the Centre for Higher Education at the University of Cape Town have also been involved in innovative work aimed at promoting multilingualism through ICT (Kaschula \& Maseko, 2014). Other institutions such as Rhodes University, the University of South Africa, Stellenbosch University, the University of Pretoria, and UKZN, among others, have also been involved in similar initiatives (Ndebele, 2014).

In the following section, we seek to contextualise the promotion of multilingualism at UKZN by providing a description of the University's language policy and plan. 


\section{The University of KwaZulu-Natal's language policy and plan}

UKZN's language policy was first adopted in 2006 and revised in 2014. The policy is founded on and supported by principles of national and provincial policy provisions, such as the South African Constitution, the Higher Education Act, the Language Policy for Higher Education and the KwaZulu-Natal provincial language policy, among other legislative provisions. This policy was formed in accordance with the 'university's vision to be a premier university of African scholarship; its mission statement to address inequalities of the past and which includes the injunction to promote and foster tolerance and respect for diverse cultural and social values...' (UKZN, 2014).

The policy recognises isiZulu and English as official languages of the university. These languages are also officially recognised as languages of administration. The policy acknowledges the dominant status of English in academic discourse, international trade and industry, and government and private institutions. Proficiency in isiZulu, on the other hand, is vital for nation building and effective communication between students and the majority of the KwaZulu-Natal populace. The university will continue to employ English as its primary academic language, while developing isiZulu as an additional language of teaching and learning in addition to resources that make language use a real possibility for communication by the overall university community. The university's bilingual policy is based upon the national policy of multilingualism, which advocates for the promotion of 'respect for diversity in language and culture'. It is hoped that, if implemented, this policy will go a long way in promoting multilingualism for social, intellectual, economic, and cultural development (UKZN, 2014).

The UKZN language policy seeks to promote bilingualism and multilingualism. This is evidenced in its aims, which include the preservation and promotion of respect and proficiency in all official languages and other heritage languages in order to enable potentially valuable cultural, economic, and scientific ties. The policy also commits the University to the development of an awareness of multilingualism by acknowledging all the official languages of the KwaZulu-Natal province and their linguistic, cultural, and communication value. In its commitment to the promotion of bilingualism and multilingualism in policy and practice, it is stated in the policy that an approach similar to that proposed for the study of isiZulu and English would be adopted to encourage the promotion and study of other languages spoken nationally and within the African continent. These languages include isiXhosa and Sesotho in South Africa, Kiswahili, French and Arabic in the continent, and emerging global languages like Mandarin (UKZN, 2014: 6).

In line with its language policy, UKZN introduced a compulsory basic isiZulu module for all non-mother tongue speakers of isiZulu and related Nguni languages in 2014, as a requirement for all degree programmes. This was done as a response to the medium- to long-term strategy of promoting bilingualism at the university. In light of this, this paper views the development and promotion of isiZulu and other African languages as a linguistic revolution. This revolution is a product of Cobarrubias's (1983) vernacularisation. Examples of vernacularisation include languages such as Kiswahili in Tanzania and Hebrew in Israel. In South Africa, vernacularisation can be exemplified through the remarkable development of Afrikaans during the apartheid era (Kamwendo, 2006). 
The following sections deal with the theoretical framework that informed the study, followed by the research methodology.

\section{The 'language as a resource' conceptual framework}

This paper is situated within the 'language as a resource' theoretical orientation. According to McNelly (2015), the language as a resource framework opts for pluralism in society as opposed to assimilation. He adds that the framework views language as a community asset which is useful in the creation of social and economic bridges among different communities (McNelly, 2015: 13). Other scholars, such as Bamgbose (2000), Baker (2011), and Ruiz (1984) have also emphasised the importance of a language as a resource approach in conceptualising multilingualism. It has been argued that the approach allows groups and individuals to participate in the world economy and world politics (Ruiz, 1984). Language as a resource constitutes the safeguarding of heritage languages and the promotion of cooperation and tolerance among different ethnic groups, and is the main element and expression of identity (Baker, 2011; Ruiz, 1984). Furthermore, it is argued that language as a natural resource is central in the cultivation of economic, commercial, cultural, spiritual, political, and educational benefits (Baker, 2011; Ruiz, 1984). Bamgbose (2000) thus contends that this particular approach would provide an understanding on what a country would benefit or lose by employing an indigenous African language as opposed to a foreign language as its national language. He adds that this approach enforces a paradigm shift from viewing multilingualism as a problem and a necessary evil to seeing it as enriching a community's sociocultural life, a virtue, an opportunity opener, and something to be sought after and envied. In the South African context, this approach recognises multilingualism as an important feature in the South African society, enforced by the recognition of 11 official languages as national resources (Pluddemann, 1997).

\section{METHODOLOGY}

Qualitative data collection procedures in a case study research design were used in this study. According to Patton (2002), a qualitative research approach involves a naturalistic approach that seeks to understand phenomena in context-specific settings, such as a real-world setting where the researcher does not attempt to manipulate the phenomenon of interest. An openended questionnaire was employed as a data collection tool. The choice of a questionnaire as data collection tool was based on maintaining confidentiality and the anonymity of respondents, as well as to avoid bias. The questionnaires were completed and submitted anonymously during class. The students who participated in this study came from the College of Law and Management Studies at the UKZN. This group of students were all part-time LLB students and full-time practising professionals.

The choice of this particular group of students was based on the assumption that they already functioned in multilingual contexts which are dominated by indigenous African language speakers. A total of 15 students participated in this study. All these students were enrolled for the basic Zulu module (ZULUN101). Ethical clearance was obtained from the UKZN Humanities and Social Sciences Research Ethics committee. The students were informed that the study sought to solicit their views about learning an African language as an additional language. The questionnaire addressed four different, though related, themes. These included 
the students' motivation for learning isiZulu as an additional language, their perceptions about learning an African language, their attitudes towards isiZulu, and their communication practices through the medium of isiZulu. The analysis of data was therefore based upon the abovementioned themes.

The ages of these students ranged between 29 and 49 years. Of all the students who returned the questionnaires, five were monolingual English speakers, five were bilingual speakers of English and Afrikaans, while one was bilingual in English and Hindi, and one was multilingual in English, Afrikaans, and Hindi. There is no desire to generalise the findings. The researchers appreciate that different groups of students have divergent views, and therefore one cannot aim at generalising findings across the board.

The following section presents data based on the different thematic categories of the questionnaire.

\section{DATA PRESENTATION}

The findings of this study are presented and discussed in the following order: various themes attached to the student responses are presented alongside the responses of students, followed by a detailed discussion of the themes pertaining to the potential significance of additive multilingualism through the learning of an African language as an additional language.

\section{Interlingual and intercultural communication}

Evidence from student responses reflect an understanding of multilingualism as a facilitator of interlingual and intercultural communication among different linguistic groups. In any multilingual context, speakers interact with people who may differ from them in terms of not only their linguistic background but also their cultural orientation. English monolingualism may become a communication barrier in interactions involving isiZulu speakers who may not be IsiZulu-English bilinguals, particularly in the province of KwaZulu-Natal. The following statements by different students confirm the above assertion:

Living in a country such as South Africa which has isiZulu and many other African languages as part of the 11 official languages, it is imperative to be versed in at the least one of the African languages. In doing so, one may be able to converse with fellow citizens in the country and more so in KwaZulu-Natal [Resp.1].

We live in Africa and for a majority of people English is not their first language and lot of people actually struggle to communicate effectively in English. Learning an African language allows you to gain insight into a different culture which enables you to better understand those around you. By speaking their language you may gain the respect of individuals who are part of that particular culture [Resp.10].

It is important. You can converse with your peers or colleagues who are of a different culture. There is no restrictions or limitations and helps enhancing further learning and development. It can be used anywhere and allows you to be versatile [Resp.9].

For various reasons, including basic communication in the work place, particularly in health setting. It also helps foster an improved awareness and knowledge of African

Per Linguam 2017 33(1):67-82

http://dx.doi.org/10.5785/33-1-692 
culture, which also contributes to better relationships and understanding in the work and domestic environment [Resp.5].

\section{Enhanced communication in social and professional domains}

Additive multilingualism is also understood to facilitate enhanced communication in social and professional domains. Most workplace domains have become multilingual since the ushering in of a democracy in 1994. This entails fair access to employment opportunities and services by different racial and linguistic groups, the right to use one's language of choice for workplace communication, and the freedom to interact with other races at a social and professional level. The following respondents' assertions attest to the above:

It was compulsory for my LLB course, but I also wanted to learn isiZulu as I often experience communication barriers in my work in occupational health [Resp.5].

To be able to have complete conversations with the majority. My profession requires that being able to speak isiZulu means being able to tap into a whole new market in the language of their preference [Resp.8].

I believe that we need to be able to communicate with non-English speakers. My other motivation is for my profession since it is of utmost importance to communicate with isiZulu speakers so that we can diagnose and treat their illness [Resp.7].

Appreciating how much isiZulu speakers have put into learning English as their second language gave me the motivation. I admire all those isiZulu speakers who speak English excellently and yet it is their second language. I hope to be able to be like them [Resp.6].

IsiZulu is a language that is spreading popularly throughout the world at present day, in KwaZulu-Natal, South Africa which is the home land of Zulu people and the origin of the isiZulu language. I found that it would be interesting to learn the native language of the place (land) that I live on. Also, being an Indian female I feel that learning the language of isiZulu will empower my opportunities in the workplace and in society [Resp.1].

\section{Changes in linguistic ideological misconceptions}

The changing of ideological misconceptions associated with multilingualism and indigenous African languages was also evident in the students' responses. Additive multilingualism expedites a shift from viewing African languages as difficult to learn and less important to an appreciation of their vitality and resourcefulness in South Africa's multilingual society. The following statements by some students attest to the above assertion:

I was reluctant to take the module but knew it would benefit. My reluctance was facing a new language. It was daunting when first attempted, but once the rules of grammar were taught, it was easier to grasp [Resp.6].

I just knew it was a difficult language to learn. Now that I have been shown basics, I no longer see isiZulu as an insurmountable challenge [Resp.5].

Per Linguam 2017 33(1):67-82

http://dx.doi.org/10.5785/33-1-692 
I thought it was difficult, of no value, how much would I use it but I was wrong [Resp.9].

Prior to starting the course I had a very nervous attitude towards the course, however now that I have gone through the course I feel very much more confident and I enjoyed my experience during this course [Resp.1].

I was annoyed that I couldn't communicate with isiZulu speakers especially my patients. Now that I can understand basic isiZulu, I have come to respect the language and feel confident in communicating with isiZulu speakers [Resp.7].

I was excited to learn something new [Resp.2].

\section{The facilitation of social cohesion}

Evidence from student responses also reflect a view of additive multilingualism as an important instrument in facilitating social cohesion among different linguistic and racial groups. The apartheid legacy in South Africa left a trail of racial divisions and tension through divide-and-rule policies. It is against such a background that embracing multilingualism is seen as instrumental in strengthening social relations and promoting acceptance among different groups. Some of the responses of the participants in this regard are as follows:

Yes, I use basic greetings and easy requests.... It was a wow! Almost all were excited for me. One isiZulu speaking client said I am now part of them [Resp.8].

Yes, since starting on the isiZulu course, I am more confident in communicating in isiZulu.... They were astonished but extremely happy that I showed an interest in learning another language [Resp.2].

Yes I did attempt to communicate with my patients and with my colleagues at work...I have had good feedback from isiZulu speakers especially since I have made an attempt to learn their language. My patients trust me to treat them even more since I can understand them [Resp.7].

However, one respondent indicated that using isiZulu at his workplace was not allowed, though the participant used it to communicate with people outside work. The participant's response was as follows:

No, for security reasons we are only permitted to speak English at work. We are regulated and face possible penalties if our employees are caught speaking another language in the work environment [Resp.10].

\section{DISCUSSION}

This section includes a discussion of the various themes that emerged from the views and experiences of students who participated in this study.

It is important at this juncture to highlight that, given South Africa's multilingual landscape, any form of additive multilingualism should embrace indigenous African languages. Such a

Per Linguam 2017 33(1):67-82

http://dx.doi.org/10.5785/33-1-692 
form of multilingualism plays a vital role in facilitating interlingual and intercultural communication in social and professional domains of life. Language is important in the creation of the social context in which it is used and creates the different ways in which speakers gain understanding of the social activities in which they are involved (Liddicoat, 2009). In South Africa's multilingual context, speakers interact with other people who not only use different languages but also come from diverse cultural backgrounds. In KwaZuluNatal, for example, more than three-quarters of the population $(78 \%)$, which translates to more than 7.9 million people, have isiZulu as their first language. English is the second-most spoken first language, at $13 \%$ of the provincial population (Statistics South Africa, 2011). This means that it is highly likely for people who come from different linguistic and cultural backgrounds to interact. Communication does not occur in a void but within a setting and a situation (Steinberg, 1994). It therefore follows that, if speakers share a language and its associated cultural conventions, the interpretation of the social dimension of language is based on shared beliefs of the importance of language in creating a social world. On the other hand, if speakers have different cultural conventions, the possibility of misunderstanding utterances and communication breakdown is greatly increased (Scollon \& Scollon, 2001). In affirmation of the above, Ntuli (2012) provides examples of non-verbal communication cues and their cultural assumptions, which could be problematic in interlingual and intercultural communication. For example, he identifies the behaviour of looking straight in the eyes of an elderly person or a person of high status, standing while speaking to an elderly person or anyone superior, the use of the left hand when receiving any object from someone, and addressing an elderly person in the singular or using their first name as culturally disrespectful (Ntuli, 2012:23-24).

Additive multilingualism also promotes social cohesion amongst different groups of people in society. Social cohesion is important in South Africa given the history of colonial and apartheid rule. During the apartheid era, South Africans were racially divided and the political situation forced different racial groups to live in isolated areas. However, the ushering in of the democratic dispensation in 1994 provided freedom from these political restrictions. In this regard, Badat and Sayed (2014) argue that the concerns for social cohesion are central to the building of a post-apartheid South Africa, a country still struggling with redressing the inequalities of the past and building a new society through reconciliation and healing. Commenting on the important role of multilingualism in promoting social cohesion, Tonkin (2003:6) argues that 'the diversity of language is an asset: it helps build cohesion in small communities and sustains unique cultures, thereby bestowing distinctive identities on individuals and reducing alienation and homogenization.'

The commitment to the promotion of social cohesion in South African communities is enshrined in the South African Constitution and other legislative documents discussed above.

The resourceful nature of African languages in South Africa's multilingual setting can also be conceptualised within the context of breaking down communication barriers in professional settings. While the hegemonic nature of English and the bilingual and multilingual competence of most African language speakers must be acknowledged, it does not necessarily follow that all African language speakers are conversant in English. Therefore, language can become a barrier to accessing information and services, particularly if English is used as the de facto language of communication. In this regard, Alexander 
(2007) argues that a policy which promotes multilingualism in work environments ensures an increase in the efficiency and possesses multiple cost-effective rewards over a policy that promotes monolingualism. Within the criminal justice profession in particular, scholars have argued that linguistic and cultural barriers present a genuine threat to the effective dispensation of justice in courts (Choshi, 2009; Hlophe, 2003; Ralarala, 2012). This is worsened by the fact that, despite the constitutional recognition of eleven official language, the languages of record in the court system remain solely English and Afrikaans. According to Ralarala (2012), South Africa's multilingual setting has serious complexities, especially in cases where the accused speaks an African language and can only rely on interpreting or translation services in order to follow the legal discourse. Ralarala (2012) further asserts that, while language barriers are not unique to South Africa, the South African situation is made unusual by the human costs resulting from this challenge in real-life situations and the sentencing of people to imprisonment, sometimes for uncommitted crimes.

In addition to the above assertions, Choshi (2009) maintains that the lack of tolerance to language diversity in the South African criminal justice system is a national problem that needs critical attention. He adds that the individual's right to a language of choice is obstructed by a further right to an interpreter in cases where trial is practically impossible in the language he/she understands. While interpretation is done for the benefit of the accused, in practice, this right is not accorded to the accused because of a potential loss of meaning, words, rules, and principles in translation (Choshi, 2009). Hlophe (2003) thus concedes that the composition of the judiciary should accommodate and reflect all the official languages. Furthermore, the appointment of judicial office bearers who can communicate through the medium of African languages would allow for recognition of the country's linguistic diversity (Hlophe, 2003).

The promotion of bilingualism and multilingualism serves to dispel ideological misconceptions about African languages perpetuated through colonial and apartheid policies. Such misconceptions are meant, in most cases, to justify English monolingualism and further propel the dominance of former colonial languages at the expense of indigenous African languages. The cost implications of multilingualism are usually overemphasised, while the benefits are underestimated or ignored (Versfeld, 2014). In support of the above, Makoni (1999) points out that there is continuity of the apartheid linguistic engineering, where languages were used as strategy to divide and rule, in the dispensation of the official recognition of 11 languages.

In expanding on misconceptions relating to multilingualism, which is a natural feature in most countries on the African continent, Ndhlovu (2008) identifies two major perspectives that have emerged as arguments against the concept of multilingualism. The first perspective associates the coexistence of many languages with various problems ranging from poverty to tribal wars and political instability. According to this particular perspective, 'the multiplicity of African languages is often seen as a setback towards achieving African unity, whether at a national, regional or continental level' (Zeleza, 2006:20). The second perspective associates linguistic diversity with economic underdevelopment, while monolingualism is hailed as an immense contributory factor to a thriving economy and political stability (Ndhlovu, 2008:138). It is upon such a background the non-mother tongue speakers of African languages, and in some cases mother tongue speakers of these languages, sometimes 
underestimate the value of indigenous African languages and the importance of speaking or learning them in preference of English monolingualism or former colonial languages form of bilingualism.

\section{CONCLUDING REMARKS}

The paper sought to explore the potential significance of additive multilingualism in promoting multilingualism in the South African society. The central argument of the paper was premised on the potential value of multilingualism that encompasses indigenous African languages. The language as a resource theoretical framework was employed as a backbone theory of the paper. The framework puts emphasis on the substantial value of multilingualism, not only as facilitating access to diverse literatures and cultures, but also an important ingredient for social cohesion, intercultural and interlingual communication, effective service delivery, and satisfaction for all citizens.

From the foregoing discussion, it is evident that an ideal type of additive multilingualism in the South African context should embrace indigenous African languages. Additive multilingualism should be promoted within the context of viewing all languages as sets of resources as opposed to problematic inflexible linguistic systems. It is therefore important to highlight that the teaching of isiZulu as an additional language to non-mother tongue speakers at the UKZN is a significant stride in contributing towards the promotion of multilingualism and the status of indigenous African languages in South Africa.

Higher education institutions in South Africa should demonstrate visible commitment to the project of multilingualism and the development of indigenous African languages in a wider context. All provincial languages and languages which enable access to other provinces should be given an opportunity to contribute to the identity of different universities. There is also a need to put in place and execute efficient plans aimed at enhancing the acquisition, status, corpus, and prestige of indigenous African languages. As such, universities and other stakeholders should collaborate in taking advantage of the resourceful nature of multilingualism that encompasses indigenous African languages as essential integral constituents.

\section{REFERENCES}

ALEXANDER, N. 2002. An ordinary country: Issues in the transition from apartheid to democracy in South Africa. Durban: University of KwaZulu-Natal Press.

ALEXANDER, N. 2007. The role of African universities in the intellectualisation of African languages. Journal of Higher Education in Africa, 5(1):29-44.

ALEXANDER, N. 2013. Thoughts on the New South Africa. Johannesburg: Jacana Media.

BADAT, S \& Y SAYED. 2014. Post-1994 South African education: The challenge of social justice. The Annals of the American Academy of Political and Social Science, 652:127148.

BAKER, C. 2011. Foundations of bilingual education and bilingualism. Bristol: Multilingual Matters.

BAMGBOSE, A. 1991. Language and the nation: The language question in sub-Saharan Africa. Edinburgh: Edinburgh University Press. 
BAMGBOSE, A. 2000. Language and exclusion: The consequences of language policies in Africa. Hamburg: LIT.

BARKHUIZEN, G. 2001. Learners' perceptions of the teaching and learning of Xhosa first language in Eastern and Western Cape high schools: Summary report. Pretoria: Pan South African Language Board.

CENOZ, J. 2013. Defining multilingualism. Annual Review of Applied Linguistics, 33:3-18.

CHOSHI, MK. 2009. Law and language: Solution for multilingual societies. In Pinto, PF, C Brohy \& J-G Türi (Eds), Direito, língua e cidadania global [Law, language and global citizenship]. Lisbon: APP. 149-164.

CHUMBOW, B. S. 2009. Linguistic diversity, pluralism and national development in Africa. Africa Development, 34(2):21-45.

COBARRUBIAS, J. 1983. Ethical issues in status planning. In Cobarrubias, J \& JA Fishman (Eds), Progress in language planning. The Hague: Mouton. 94-110.

DE KLERK, V. 1996. Use of and attitudes to English in a multilingual University. English World-Wide, 17(1):111-127.

DE KLERK, V. 2000. To be Xhosa or not to be Xhosa... That is the question. Journal of Multilingual and Multicultural Development, 21:198-215.

DEPARTMENT OF ARTS AND CULTURE. 2003. National language policy framework. Pretoria: Government Printers.

DEPARTMENT OF EDUCATION. 2002. Language policy for higher education. Pretoria: Government printers.

DEPARTMENT OF EDUCATION. 2003. The development of indigenous African languages' as mediums of instruction in higher education. Ministerial committee's report to the Minister of Education. Pretoria: Government Printers.

DEPARTMENT OF EDUCATION. 2008. Ministerial committee report on transformation and social cohesion and the elimination of discrimination in public Higher Education institutions. Pretoria: Government Printers.

DEPARTMENT OF HIGHER EDUCATION AND TRAINING. 2011. Report commissioned by Minister of Higher Education and Training for the Charter for Humanities and Social Sciences. Pretoria: Government Printers.

DEPARTMENT OF HIGHER EDUCATION AND TRAINING. 2013. White paper for postsecondary school education and training. Pretoria: Government Printers.

DYERS, C. 1998. Xhosa students' attitudes towards black South African languages at the University of the Western Cape. South African Journal of African Languages, 19(2):7382.

HEUGH, K. 2000. The case against bilingual and multilingual education. PRAESA Occasional Paper No. 6. Cape Town: PRAESA.

HLOPHE, JM. 2003. Receiving justice in your own language: The need for effective court interpreting in multilingual society. Paper delivered at the University of Cape Town on 17 September 2003. Available from http://www.sabar.co.za/lawjournals/2004/april/2004-april-vol017-no1-pp42-47.pdf [Accessed: 22 May 2017]

KAMWENDO, G, N HLONGWA \& N MKHIZE. 2014. On medium of instruction and African scholarship: The case of IsiZulu at the University of KwaZulu-Natal in South Africa. Current Issues in Language Planning, 15(1):75-89.

Per Linguam 2017 33(1):67-82

http://dx.doi.org/10.5785/33-1-692 
KAMWENDO, GH. (2006). No easy walk to linguistic freedom: A critique of language planning during South Africa's first decade of democracy. Nordic Journal of African Studies, 15(1):53-70.

KASCHULA, RH \& P MASEKO. 2014. The intellectualisation of African languages, multilingualism and education: A research-based approach. Alternation: Special Edition, 13:8-35.

KASCHULA, RH. 2004. South Africa's National Language Policy revisited: The challenge of implementation. Alternation, 11(2):10-25.

LIDDICOAT, AJ. 2009. Communication as culturally contexted practice: A view from intercultural communication. Australian Journal of Linguistics, 29(1):115-133.

MADIBA, M. 2010. Fast-tracking concept learning to English as an additional language students through corpus-based multilingual glossaries. Alternation, 17(1):225-248.

MAKONI, S. 1999. African Languages as Colonial Scripts. In Nutall, S \& C Coetzee (Eds), Negotiating the past: The making of memory in South Africa. Cape Town: Oxford University Press. 242-248.

MAVESERA, M. 2011. Situating African languages in the global village for sustainable development: Attractions and challenges for Zimbabwe. Journal of Language and Culture, 2(5):72-81.

MAY, S. 2004. Rethinking linguistic human rights: answering questions of identity, essentialism and mobility. In Freeland, J \& D Patrick (Eds), Language rights and Language survival: Sociolinguistic and sociocultural perspectives. Manchester: St Jerome. 35-53.

MAZRUI, AA \& AM MAZRUI. 1998. The power of Babel: Language and governance in the African experience. Oxford: James Currey.

MCNELLY, AC. 2015. Language learning policy through the lens of language as a problem, as a right and as a resource. NABE Journal of Research and Practice, 6:1-22.

NDEBELE, H. 2014. Promoting indigenous African languages through information and communication technology localisation: A language management approach. Alternation Special Issue, 13:102-127.

NDHLOVU, F. 2008. Language and African development: Theoretical reflections on the place of languages in African studies. Nordic Journal of African Studies, 17(2):137151.

NDIMANDE-HLONGWA, N \& G MAZIBUKO. 2016. IsiZulu at the University of KwaZulu-Natal: Prospects for teaching isiZulu as a Second Language for Specific Purposes. In Kaschula, RH \& E Wolff (Eds), Additional language teaching and use in multilingual education in Africa: Concepts and practices. Pretoria: UNISA. 149-161.

NDIMANDE-HLONGWA, N \& R WILDSMITH. 2010. Multilingualism for access, language development and language intellectualization. Alternation Special Issue, 17(1):1-3.

NTULI, CD. 2012. Intercultural misunderstanding in South Africa: An analysis of non-verbal communication behaviour in context. Intercultural Communication Studies, 21(2):2031.

PATTON, MQ. 2002. Qualitative evaluation and research methods (3rd ed.). Thousand Oaks, CA: Sage.

PLUDDEMANN, P. 1997. 'Additive' and 'subtractive': Challenges in education for multilingualism. Per Linguam, 13(1):17-28.

Per Linguam 2017 33(1):67-82

http://dx.doi.org/10.5785/33-1-692 
RALARALA, MK. 2012. A compromise of rights of language and rights to a language in Eugene Terre'Blanche's trial within a trial: Evidence lost in translation. Stellenbosch Papers in Linguistics, 41(1):55-70.

RUÍZ, R. 1984. Orientations in language planning. NABE: The Journal for the National Association for Bilingual Education, 8(2):15-34.

SCOLLON, R \& SW SCOLLON. 2001. Intercultural communication: A discourse approach. Oxford: Blackwell.

SOUTH AFRICA. 1996. Constitution of the Republic of South Africa Act, No. 108 of 1996. Pretoria: Government Printers.

SOUTH AFRICA. 1997. Higher Education Act, No. 101 of 1997. Pretoria: Government Printers.

STATISTICS SOUTH AFRICA. 2011. Provincial profile: KwaZulu-Natal. Pretoria: Statistics South Africa.

TONKIN, H. 2003. Language and society. New York, NY: American Forum for Global Education.

UNIVERSITY OF KWAZULU-NATAL. 2014. Language policy of the University of KwaZulu-Natal. Durban: University of KwaZulu-Natal.

VAN GINKEL, AJ. 2014. Additive language learning for multilingual settings. JBS International. Available from http://pdf.usaid.gov/pdf_docs/PA00JW1R.pdf [Accessed: 8 June 2017].

VERSFELD, M. Economics of multilingualism: Reconsidering language policies for South Africa. Tydskrif vir Geesteswetenskappe, 54(2):217-234.

WEBB, V. 2002. Language in South Africa: The role of language in national transformation, reconstruction and development. Philadelphia, PA: John Benjamins.

WEBB, VN. 1996. English and language planning in South Africa: The flip side. In De Klerk, V (Ed.), Focus on South Africa. Amsterdam: John Benjamins.

ZELEZA, PT. 2006. The inventions of African identities and languages: The discursive and development implications. In Selected proceedings of the 36th conference of African linguistics. Somerville, MA: Cascadilla Proceedings Project. 14-26. 